\title{
Prevalence of upper extremity pain in a population of people with paraplegia
}

\author{
Y. Kentar ${ }^{1} \cdot$ R. Zastrow ${ }^{1} \cdot$ H. Bradley ${ }^{1} \cdot$ M. Brunner ${ }^{1} \cdot$ W. Pepke ${ }^{1} \cdot$ T. Bruckner $^{2} \cdot$ P. Raiss ${ }^{1} \cdot$ A. Hug $\mathbb{D}^{3} \cdot$ H. Almansour ${ }^{1}$. \\ M. Akbar ${ }^{1}$
}

Received: 17 July 2017 / Revised: 15 December 2017 / Accepted: 19 December 2017 / Published online: 24 January 2018

(c) International Spinal Cord Society 2018

\begin{abstract}
Study design Cross-sectional study.

Objectives To determine the prevalence, patterns, and predictors of musculoskeletal pain in the upper extremity joints among wheelchair-dependent individuals with post-traumatic paraplegia. Secondarily, to document most common reported causes of upper extremity pain.

Setting Centre for Orthopaedics, Trauma Surgery and Spinal Cord Injury, Germany.

Methods The study was done by means of a structured questionnaire, which was mailed to the individuals who had been treated between 1990 and 2007 for newly sustained or pre-existing, accident-related paraplegia $(n=670)$. The questionnaire was designed mainly to obtain the information regarding shoulder, elbow, and wrist pain. Additional data included participant demographics, mechanism, level and completeness of injury as well as wheelchair dependence and time since injury. The Frankel classification system was used to define the completeness of injury.

Results Four hundred and fifty-one (67\%) questionnaires were included. Pain was reported by approximately $81 \%$ of the participants. Of this sample, $61 \%$ had shoulder pain, 33\% had elbow pain, and $43 \%$ had wrist pain, $19 \%$ had shoulder, elbow, and wrist pain, 27\% had shoulder and elbow pain, 34\% had shoulder and wrist pain, $21 \%$ had elbow and wrist pain. The main diagnoses were rotator cuff tears for individuals with shoulder pain, epicondylitis for those with elbow pain, and carpal tunnel syndrome for those with wrist pain. The development of shoulder/elbow and wrist pain correlated with age and time since injury.

Conclusions Age and the length of time since injury correlated with a higher rate of shoulder, elbow, and wrist pain. The completeness of injury, neurological level, and gender were correlated with shoulder, elbow, and wrist pain, respectively.
\end{abstract}

\section{Introduction}

As the life expectancy for individuals with spinal cord injury (SCI) continues to increase $[1,2]$, issues related to quality of life and age-related diseases such as musculoskeletal problems are of importance.

M. Akbar

michael.akbar@med.uni-heidelberg.de

1 Department of Orthopaedic Surgery, Trauma Surgery and Spinal Cord Injury, University of Heidelberg, Heidelberg, Germany

2 Institute of Medical Biometry and Informatics, University of Heidelberg, Heidelberg, Germany

3 Spinal Cord Injury Center, University of Heidelberg, Heidelberg, Germany
Studies have shown that wheeling and other daily functional activities result in massive strain on the upper extremity joints and soft tissues when compared to the ablebodied population [3-5]. Others have investigated the physioanatomic changes (e.g., increased strength) associated with the sudden overuse of upper limbs and demonstrated a link to acute and chronic pain [4-8]. There is no clear agreement in the literature regarding critical issues such as the influence of age and duration of wheelchair dependence on the upper extremity (shoulder, elbow, and wrist) pain and its prevalence post-SCI, as the samples studied were diverse with respect to age, gender, duration, and level of SCI as well as geographical region [4, 9-12].

Although pathological conditions of the shoulder and wrist joints in individuals with paraplegia who are wheelchair dependent have been extensively studied [3, 13-19], only a few studies focused on the prevalence of elbow pain 
and its etiologies [20-22]. Several previous studies have focused primarily on the prevalence of wrist pain. However, its predictors have not been well studied, as the results may have been influenced by the fact that they included other sources of upper extremity pain (e.g., shoulder) in their overall analyses [4, 21, 23-25].

Our study represents a continuation of the research conducted over the past decades to extend the current knowledge of musculoskeletal pain after SCI. The primary objectives of the current descriptive cross-sectional study were to determine the prevalence and patterns of musculoskeletal pain in the upper extemity joints (shoulder, elbow, and wrist) and the correlation with age, gender, time since injury, completeness of injury, and neurological level of injury (NLI) in a wheelchair-dependent population with post-traumatic paraplegia living in Germany. A secondary objective was to document the most common causes of pain in upper extremity joints.

\section{Methods}

After obtaining the institutional review board approval, a database search was conducted for patients who were treated at Heidelberg University Hospital between 1990 and 2007 for newly sustained or pre-existing, accident-related paraplegia. These records were reviewed to obtain the following information: (1) date and mechanism of injury, (2) completeness of injury, (3) demographic information, (4) concomitant medical conditions, (5) time since injury, and (6) NLI. Frankel Grade Classification was used to determine the completeness of injury. A complete SCI is defined as a total loss of sensation and muscle function below the level of injury (Grade A), as opposed to an incomplete paraplegia which involves preservation of motor or sensory function below the level of injury (Grades B, C, and D) [26]. Those with Grade D were not totally wheelchair dependent and were therefore excluded from the study. NLI was grouped as either "high paraplegia" (thoracic level T2-T7) or "low paraplegia" (below T7).

Furthermore, individuals were excluded if they (1) had an active infection in their upper extremity, (2) were not mentally able to complete the questionnaire, (3) had known cervical disc herniation, cervical and thoracic syringomyelia, tetraplegia, or advanced spinal degenerative joint disease, and (4) had a history of upper extremity softtissue injury (e.g., brachial plexus injury, tendon rupture, or dislocation). Accordingly, 670 individuals with paraplegia were initially included, and a questionnaire was mailed to all and asked to identify the cause of their injuries, their demographics, the location of their pain, the nature of their pain treatment, and their levels of neurological lesions using a combination of short answers, yes/no responses, and pictorial representations. Then, they provided their clinical notes, X-rays, computed tomography (CT) scans, magnetic resonance imaging (MRI) scans, ultrasounds, and/or electrophysiological exam results for analysis. All diagnostic procedures should have been done within the last 3 months prior to the survey to be included in the analysis. Those who could not provide these data were excluded from the study. Finally, individuals whose data regarding SCI were missing were contacted by phone to obtain the required data.

Figure 1 illustrates the inclusion and exclusion process of our study cohort.

\section{Statistical analysis}

The survey data were compiled at the Institute of Medical Biometry and Informatics. Continuous data were reported as mean, standard deviation (SD), median, and range. Categorical data were reported as absolute and relative frequencies in terms of numbers and percentages. An unpaired $t$-test and $\chi^{2}$ analysis were used for statistical significance testing for continuous (age and time since injury in years) and categorical variables (gender, NLI (T2-T7 vs. below T7), and completeness of injury), respectively. Associated factors (variables of interest) for shoulder, elbow, and wrist pain including age, gender, time since injury, completeness, and NLI were outlined in this cross-sectional study using descriptive statistics. Multivariate logistic regression analysis was used to examine the potential influence of the abovementioned parameters on the presence of pain. Odds ratios and their corresponding $95 \%$ confidence intervals were calculated. All analyses were carried out using SAS 9.1 software. The level of significance was set at $5 \%$.

\section{Results}

Four hundred and fifty-one individuals (67\%) meeting our inclusion criteria responded to the questionnaire and were included in the study (322 men and 129 women). The average age of the cohort was 49.4 years (SD of 14.9, median 50, interquartile range: 40-61). Age at injury was 29.1 years (SD 16.3, median 24.0, interquartile range: 18-38). At the time of the survey, time since injury ranged from 0.7 to 65.5 years, with a mean of 20.9 years (SD 13.1, median 19.9, interquartile range: 10-32). Overall, 65\% had complete paraplegia and $33 \%$ had incomplete paraplegia. Seven participants (2\%) did not answer this question and we could not obtain it from their medical records.

The causes of paraplegia were motor vehicle accidents $(57 \%)$, falls $(21 \%)$, work-related accidents (10\%), and sports-related accidents (4\%). "Other accident causes" accounted for $7 \%$ and included gunshot injuries, suicide attempts, or surgery. Three participants did not answer this question. 
Fig. 1 Flow diagram illustrating the process of inclusion and exclusion of the study cohort
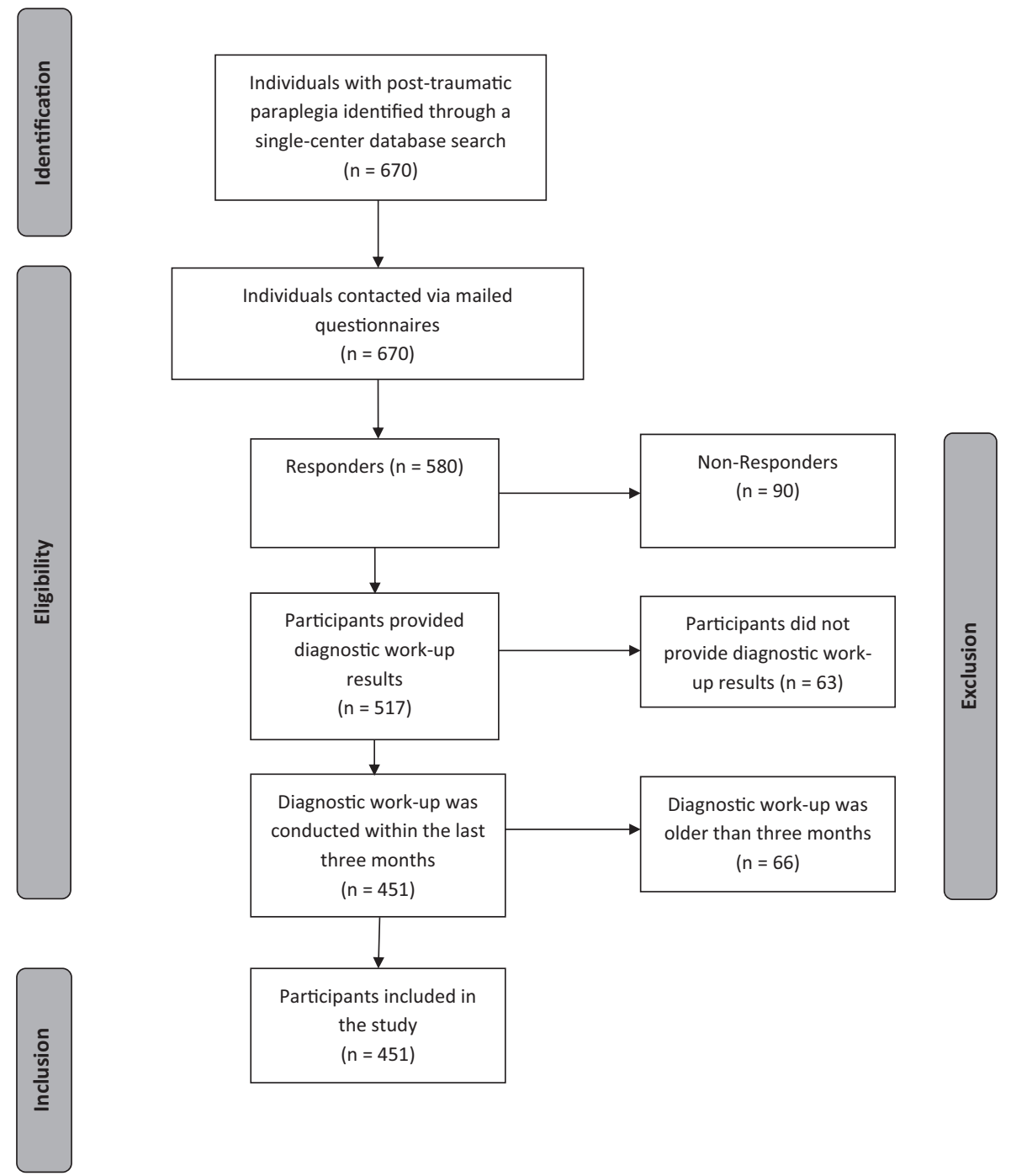

Two hundred and thirty-six participants (52\%) had high paraplegia and 211 (47\%) had low paraplegia. Four participants $(1 \%)$ failed to specify their lesion levels and we could not obtain it from their medical records. The demographic data are summarized in Table 1.

Pain was reported by approximately $81 \%$ of the participants: $61 \%$ had shoulder pain, $33 \%$ had elbow pain, and $43 \%$ had wrist pain. Nineteen percent had shoulder, elbow, and wrist pain, 27\% had shoulder and elbow pain, $34 \%$ had shoulder and wrist pain, and $21 \%$ had elbow and wrist pain.

\section{Shoulder joint}

Four hundred and forty-eight participants (99\%) responded to the question about current shoulder pain. Of those, $61 \%$ had shoulder pain to some degree. Sixty-six percent of participants with complete paraplegia had shoulder pain compared to $53 \%$ of those with incomplete paraplegia. The participants with shoulder pain were on average 6 years older than those without $(p<0.0001)$.

In fifty-four participants (20\%), the pain was due to rotator cuff tears; in $21 \%$ shoulder pain was caused by bursitis and tendinitis. Shoulder joint arthritis was diagnosed in $8 \%$ of the cases.

In the multivariate logistic regression analysis, the odds of developing shoulder pain increased by $3 \%$ with each year of life (OR $=1.030,95 \%$ CI $(1.015-1.046), p<0.001)$. In relation to the time since injury, the odds of developing shoulder pain increased by $2.4 \%$ per annum $(\mathrm{OR}=1.002$, 95\% CI (1.000-1.003), $p<0.001)$. The rate of shoulder pain was also found to be higher in participants with higher level of injury. In addition, the odds of developing pain was significantly higher in participants with complete paraplegia than in participants with incomplete paraplegia $(\mathrm{OR}=$ $1.691,95 \%$ CI $(1.089-2.625), p=0.005)$. The results from univariate and multivariate logistic regression analyses for shoulder pain are summarized in Table 2. 
Table 1 Participant characteristics $(n=451)$

\begin{tabular}{ll}
\hline Variable & Data* \\
\hline Age (years) & $49.4 \pm 14.9$ \\
Time since injury (years) & $20.9 \pm 13.1$ \\
Gender & \\
$\quad$ Male & $322(71 \%)$ \\
$\quad$ Female & $129(29 \%)$ \\
Level of injury & \\
T2-T7 & $236(52 \%)$ \\
Below T7 & $211(47 \%)$ \\
Unknown & $4(1 \%)$ \\
Completeness of injury & \\
Complete & $294(65 \%)$ \\
Incomplete & $150(33 \%)$ \\
Unknown & $7(2 \%)$ \\
Mechanism of injury & \\
Motor vehicle accidents & $257(57 \%)$ \\
Falls & $96(21 \%)$ \\
Work related accidents & $46(10 \%)$ \\
Sports related accidents & $18(4 \%)$ \\
Other causes & $31(7 \%)$ \\
Unknown & $3(1 \%)$ \\
\hline
\end{tabular}

*Values are mean \pm standard deviation $(\mathrm{SD})$ or $n(\%)$

\section{Elbow joint}

All participants answered the question regarding current elbow joint pain. One hundred and forty-seven (33\%) reported elbow joint pain; $40 \%$ of 236 participants with high level of injury had elbow pain, compared to $28 \%$ of 211 participants with low level of injury. The participants with elbow joint pain were on average 4 years older than those without $(p=0.011)$. They were fully wheelchair dependent on average 3.4 years longer than those without $(p=0.011)$.

Elbow pain was caused by epicondylitis in $29 \%$. "Other causes" were also mentioned by $35 \%$. In $12 \%$ of the cases tennis elbow was cited, and in $8 \%$ overuse was cited.

The multivariate logistic regression analysis revealed that the odds of developing elbow pain increased by $1.8 \%$ per annum $(\mathrm{OR}=1.018,95 \%$ CI $(1.003-1.034), p<0.011)$. The participants with high level of injury reported elbow pain more often than those with low-level lesions $(\mathrm{OR}=$ $1.56,95 \%$ CI $(1.019-2.387), p=0.022)$. The results from univariate and multivariate logistic regression analyses for elbow pain are summarized in Table 3 .

\section{Wrist joint}

All participants answered the question regarding current wrist pain. One hundred and ninety-five participants (43\%) had wrist pain; $36 \%$ of 322 men and $63 \%$ of 129 women reported wrist pain.

The participants with wrist pain were on average 6 years older and had been wheelchair dependent for 4.2 years longer than the participants without $(p<0.0001)$. The pain was due to carpal tunnel syndrome (CTS) in $25 \%$ of cases, where women were affected twice as often as men. In approximately $19 \%$ of the cases, the causes were found to be tendinitis, and in $19 \%$ due to rhizarthrosis. Longer time since injury was associated with high rates of wrist pain $(p$ $<0.0007)$.

The multivariate logistic regression analysis showed that with each additional year of wheelchair dependence, the odds of developing wrist pain increased by $3 \%$ $(\mathrm{OR}=1.033, \quad 95 \% \quad$ CI $\quad(1.017-1.049), \quad p<0.001)$. Women were susceptible to wrist pain three times more often than men $(\mathrm{OR}=3.13,95 \%$ CI $(2.00-4.90)$, $p<0.001)$. The results from univariate and multivariate logistic regression analyses for wrist pain are summarized in Table 4.

\section{Discussion}

In addition to neuropathic pain, musculoskeletal pain can also be debilitating for people living with SCI. Besides its negative economic consequences in terms of increased health care costs and lost productivity, pain can severely diminish an individual's social and psychological wellbeing [27-29].

In this study, we demonstrate that long-term wheelchair use is associated with upper extremity pain in $81 \%$ of the participants with chronic paraplegia. Furthermore, we show that shoulder joints $(61 \%)$ are more commonly afflicted with pain than wrist (43\%) and elbow (33\%) joints. Frequently, upper extremity pain affects not only one but several joints. Pain associated factors were: older age, longer time since injury (shoulder, elbow, wrist), lesion completeness (shoulder), higher NLI (elbow), and female gender (wrist).

Chronic shoulder pain commonly results from wear-andtear mechanisms associated with daily wheelchair use such as propulsion, transfers, and overhead movements, causing overuse-type symptoms [10, 30-32]. In this study, which only included individuals with post-traumatic paraplegia, we found a prevalence of shoulder pain of $61 \%$, which is similar to that reported in a survey of 770 individuals with paraplegia [7]. There is certainly a large variability in reported prevalence rates for shoulder pain in the literature in people with paraplegia (range 30-75\%) depending on study design and study population characteristics (e.g., age, gender, acute vs. chronic SCI, duration and level of SCI) [4, 5, 8-10, 23, 24, 31, 33-35]. 
Table 2 Univariate and multivariate analyses of factors associated with shoulder pain

\begin{tabular}{|c|c|c|c|c|c|}
\hline \multirow[t]{2}{*}{ Variable } & \multicolumn{3}{|l|}{ Univariate analysis } & \multicolumn{2}{|c|}{ Multivariate analysis } \\
\hline & With pain $(n=276)$ & $\begin{array}{l}\text { Without } \\
\text { pain }(n= \\
172)\end{array}$ & $p$ value & $\begin{array}{l}\text { OR }(95 \% \\
\text { CI })\end{array}$ & $p$ value \\
\hline Age (years) & $52.3 \pm 13.7$ & $45.7 \pm 15.8$ & $<0.0001^{*}$ & 1.030 & \\
\hline$(1.015-1.046)$ & $<0.001^{*}$ & & & & \\
\hline Time since injury (years) & $23.0 \pm 13.2$ & $17.6 \pm 12.3$ & $<0.0001^{*}$ & 1.002 & \\
\hline$(1.000-1.003)$ & $<0.001 *$ & & & & \\
\hline \multicolumn{6}{|l|}{ Gender } \\
\hline Male & $193(60 \%)$ & $129(40 \%)$ & 0.3 & 1.308 & \\
\hline$(0.831-2.059)$ & 0.181 & & & & \\
\hline Female & & & & & $\begin{array}{l}84 \\
(65 \%)\end{array}$ \\
\hline \multicolumn{6}{|l|}{$45(35 \%)$} \\
\hline \multicolumn{6}{|l|}{ Level of injury } \\
\hline $\mathrm{T} 2-\mathrm{T} 7$ & $153(65 \%)$ & $83(35 \%)$ & 0.1 & 1.416 & \\
\hline$(0.933-2.149)$ & 0.064 & & & & \\
\hline Below T7 & & & & & $\begin{array}{l}121 \\
(57 \%)\end{array}$ \\
\hline \multicolumn{6}{|l|}{$90(43 \%)$} \\
\hline \multicolumn{6}{|l|}{ Completeness of injury } \\
\hline Complete & $193(66 \%)$ & $101(34 \%)$ & $0.0079^{*}$ & 1.619 & \\
\hline$(1.089-2.625)$ & $0.005^{*}$ & & & & \\
\hline Incomplete & & & & & $\begin{array}{l}79 \\
(53 \%)\end{array}$ \\
\hline $71(47 \%)$ & & & & & \\
\hline
\end{tabular}

Values are mean \pm standard deviation (SD) or $n(\%)$

OR odds ratio, $95 \%$ CI $95 \%$ confidence interval

*Statistically significant

Table 3 Univariate and multivariate analyses of factors associated with elbow pain

\begin{tabular}{|c|c|c|c|c|c|}
\hline \multirow[t]{2}{*}{ Variable } & \multicolumn{3}{|c|}{ Univariate analysis } & \multicolumn{2}{|l|}{ Multivariate analysis } \\
\hline & $\begin{array}{l}\text { With pain }(n= \\
147)\end{array}$ & $\begin{array}{l}\text { Without pain }(n= \\
304)\end{array}$ & $p$ value & OR $(95 \% \mathrm{CI})$ & $p$ value \\
\hline Age (years) & $52.3 \pm 13.2$ & $48.5 \pm 15.6$ & $<0.011 *$ & $1.018(1.003-1.034)$ & $<0.011 *$ \\
\hline $\begin{array}{l}\text { Time since injury } \\
\text { (years) }\end{array}$ & $23.2 \pm 12.6$ & $19.7 \pm 13.2$ & $<0.007 *$ & $1.001(0.999-1.002)$ & $<0.009 *$ \\
\hline \multicolumn{6}{|l|}{ Gender } \\
\hline Male & $99(31 \%)$ & $223(69 \%)$ & 0.185 & $1.419(0.910-2.214)$ & 0.113 \\
\hline Female & $48(37 \%)$ & $81(63 \%)$ & & & \\
\hline \multicolumn{6}{|l|}{ Level of injury } \\
\hline $\mathrm{T} 2-\mathrm{T} 7$ & $87(37 \%)$ & $149(63 \%)$ & $0.034 *$ & $1.560(1.019-2.387)$ & $0.022^{*}$ \\
\hline Below T7 & $58(27 \%)$ & $153(73 \%)$ & & & \\
\hline \multicolumn{6}{|c|}{ Completeness of injury } \\
\hline Complete & $104(35 \%)$ & $190(65 \%)$ & 0.087 & $1.378(0.868-2.189)$ & 0.054 \\
\hline Incomplete & $41(27 \%)$ & $109(73 \%)$ & & & \\
\hline
\end{tabular}

Values are mean \pm standard deviation (SD) or $n(\%)$

OR odds ratio, $95 \%$ CI 95\% confidence interval

*Statistically significant 
Table 4 Univariate and multivariate analyses of factors associated with wrist pain

\begin{tabular}{|c|c|c|c|c|c|}
\hline \multirow[t]{2}{*}{ Variable } & \multicolumn{3}{|c|}{ Univariate analysis } & \multicolumn{2}{|l|}{ Multivariate analysis } \\
\hline & $\begin{array}{l}\text { With pain }(n= \\
196)\end{array}$ & $\begin{array}{l}\text { Without pain }(n= \\
255)\end{array}$ & $p$ value & OR $(95 \% \mathrm{CI})$ & $p$ value \\
\hline Age (years) & $53.3 \pm 14$ & $47.1 \pm 15.1$ & $<0.0001^{*}$ & $1.033(1.017-1.049)$ & $<0.001 *$ \\
\hline $\begin{array}{l}\text { Time since injury } \\
\text { (years) }\end{array}$ & $22.7 \pm 13$ & $18.5 \pm 13$ & $<0.0007^{*}$ & $1.000(0.999-1.002)$ & $0.014 *$ \\
\hline \multicolumn{6}{|l|}{ Gender } \\
\hline Male & $114(36 \%)$ & $208(64 \%)$ & $0.0001 *$ & $3.128(1.996-4.902)$ & $<0.001 *$ \\
\hline Female & $81(63 \%)$ & $48(37 \%)$ & & & \\
\hline \multicolumn{6}{|l|}{ Level of injury } \\
\hline $\mathrm{T} 2-\mathrm{T} 7$ & $98(42 \%)$ & $138(58 \%)$ & 0.45 & $0.983(0.650-1.488)$ & 0.271 \\
\hline Below T7 & $95(45 \%)$ & $116(55 \%)$ & & & \\
\hline \multicolumn{6}{|c|}{ Completeness of injury } \\
\hline Complete & $128(44 \%)$ & $166(56 \%)$ & 0.086 & $0.983(0.753-1.848)$ & 0.459 \\
\hline Incomplete & $64(43 \%)$ & $86(57 \%)$ & & & \\
\hline
\end{tabular}

Values are mean \pm standard deviation (SD) or $n(\%)$

OR odds ratio, $95 \%$ CI 95\% confidence interval

*Statistically significant
Controversial results with respect to predictors of shoulder pain have been presented in the literature. While some studies indicated that longer time of injury represents an independent predictor $[9,23,24,35]$, others have been inconclusive or contradictory $[4,5,8,21,36]$. Given the obvious link between age and time since injury, it is quite difficult to determine the precise influence of age alone on the development of pain. Gironda et al. found that shoulder pain positively correlates with the duration of wheelchair dependence but not with age [7]. Likewise, Akbar et al. reported that length of time since injury plays a major role in the development of rotator cuff tears in people with paraplegia and that age is of secondary importance [3]. On the other hand, Sie et al. reported that the prevalence of upper limb pain decreased slightly in individuals with paraplegia lasting more than 20 years [4]. Similar findings were reported by Barbetta et al. with higher shoulder pain rates observed in individuals with injury lasting less than 1 year [25]. Both studies argued that subjects with longer time of injury may gain new skills and develop new strategies to improve muscle strength for performing daily living activities and thus experience reduced pain. It is worth mentioning that the results of these studies may have been influenced by the fact that they included other sources of pain (such as wrist pain) in their overall analysis. In the current study, we found that the odds of developing shoulder pain increased by $3 \%$ with each year of life for individuals with paraplegia. Longer length of time since injury increased the odds by $2.4 \%$ per annum. Thus, both factors represented independent predictors of shoulder pain. While these data seem innocuous on an annual basis alone, their importance becomes clear over time as life expectancy increases.

The majority $(>70 \%)$ of shoulder pain reported among individuals with paraplegia is believed to be due to mechanical impingement and soft-tissue damage such as tendinitis [37]. These findings are partly in concordance with ours, where rotator cuff tear and tendinitis were the most common causes of shoulder pain. Samuelsson et al. reported a prevalence of shoulder pain up to $37 \%$, and $70 \%$ of these had a rotator cuff tear [8]. Similarly, Akbar et al. showed that the prevalence of rotator cuff tears was significantly higher in the group with paraplegia compared to able-bodied volunteers (63\% vs. 15\%) [3]. Interestingly, high muscle forces were found to be associated with less shoulder pain intensity [11]. Hence, we believe that the cause of shoulder pain is more likely to be a combination of overuse, poor sitting posture, repetitive overhead arm positioning, scapula-thoracic dyskinesia, and the development of muscle imbalance.

There is also a reported connection between NLI and shoulder pain; higher lesion levels appear to increase the risk of developing musculoskeletal pain [38-41]. Previous studies reported greater shoulder movement deficits and higher rates of rotator cuff tears in individuals with an SCI level above T7 [38, 42]. Our study tested that hypothesis with respect to shoulder pain. While the present study found no statistically significant difference related to the level of injury, we did find that participants with complete paraplegia experienced shoulder pain more often with an odds ratio of 1.7. The negative impact of complete injury on the prevalence of shoulder pain has been recently investigated 
in a prospective cohort study. The authors have associated shoulder pain with the decreased postural trunk control that is related to the lower muscular strength observed in those individuals with complete injuries [14]. Based on a survey obtained from 482 individuals with SCI, Noreau et al. reported that shoulder pain was also more common in individuals with complete injuries [36]. In a multifaceted longitudinal study, completeness of injury itself was associated only with decreased shoulder range of motion but not shoulder pain [43].

There are limited data on the prevalence of elbow pain in individuals with paraplegia. In our study, the prevalence was 33\%. Similar rates have been reported by Dalyan et al. and Pentland et al. (35\% and 31\%, respectively) [21, 24]. In other studies, the prevalence is reported as $5-23 \%[4,20$, 23]. Elbow pain associated with chronic overuse has been widely studied in the able-bodied population, and its most common pathology is lateral epicondylitis (i.e., tennis elbow) [44] and it occurs in those who frequently perform forceful and repetitive movements [45]. Wheelchair users in particular have an elevated risk of developing epicondylitis [5, 21]. In this study, 43 persons (29\%) who reported elbow pain were diagnosed with an inflammatory condition such as epicondylitis. This is in contrast to the $0.004-0.007 \%$ of the general able-bodied population that suffers from epicondylitis [46, 47].

Advanced age, high level of injury, and longer time since injury were significantly correlated with the presence of elbow pain. Lack of information on the net impact of these parameters on the development of pain makes it difficult to compare present results with several previous publications.

In the current study, the estimated prevalence of wrist pain of $43 \%$ lies within the reported range (15-48\%) in the literature $[4,21,24,48]$. We found that the prevalence of wrist pain appears to be related to the duration of SCI. Long-term stresses on the sensitive structures of the wrist due to pressure, hyperextension, and microtrauma likely influence the complaints in older individuals with an odds ratio of $3.3 \%$ per annum [19, 49]. Additionally, women were found to experience wrist pain more frequently than men with an odds ratio of 3.13. Since the majority of studies investigating the prevalence of wrist pain in the population with paraplegia has focused on the CTS and associated factors, it is not possible to make a fair comparison with our results $[4,16,18,19,50]$.

CTS was the most common pathology for participants, being diagnosed in $25 \%$. This is lower than the prevalence of CTS in the literature on persons with paraplegia, which is found to be between $40 \%$ and $78 \%[4,16,18,19,50]$. This disparity could be attributed mainly to the subjectivity of the diagnostic criteria and to the fact that people with CTS could present with paresthesia but not with pain, which would lead to an underestimation of our reported prevalence.

With respect to the etiology of CTS in the population with paraplegia, Gellman et al. concluded that CTS occurs in people with paraplegia as a result of repetitive trauma from wheelchair use and ischemia secondary to repetitive rather than chronic increases in pressure in the carpal tunnel [16]. This has been supported by other investigations [17, 51].

Women were found to report CTS twice as often as men. Interestingly, this dichotomy holds true for the general population as well [52-55]. Two studies have failed to find such a correlation in individuals with paraplegia $[18,50]$. Further research is required to validate these findings.

\section{Limitations}

The study has several limitations. As indicated, the study design is cross-sectional, which limits the assessment of causality. Furthermore, the study was done by means of a questionnaire and the participants were not evaluated directly. In addition, the diagnoses were probably made by different people based on different criteria, hence may not be consistent for similar pathologies. This could undoubtedly influence the significance of the observed results. Another main limitation is the response behavior, which could have opposing effects on these results. For example, individuals in pain may have been more interested and thus more likely to participate in the present study, but pain-related interference may also have made it less likely that people in pain actually answered the questionnaire and participated.

\section{Conclusion}

Age and the length of time since injury correlated with a higher rate of shoulder, elbow, and wrist pain. The completeness of injury, neurological level, and gender were correlated with shoulder, elbow, and wrist pain, respectively.

On the basis of these findings, strategies for the management and prevention of upper extremity pain would be of paramount benefit in this unique population.

Acknowledgements We acknowledge that the Frankel Grade Classification was used to determine the severity of spinal cord injury for individuals who were treated in our hospital between 1990 and 2007 and enrolled in the study.

\section{Compliance with ethical standards}

Conflict of interest The authors declare that they have no conflict of interest. 


\section{References}

1. Middleton JW, Dayton A, Walsh J, Rutkowski SB, Leong G, Duong S. Life expectancy after spinal cord injury: a 50-year study. Spinal Cord. 2012;50:803-11.

2. Saunders LL, Selassie AW, Hill EG, Nicholas JS, Varma AK, Lackland DT, et al. Traumatic spinal cord injury mortality, 19811998. J Trauma. 2009;66:184-90.

3. Akbar M, Balean G, Brunner M, Seyler TM, Bruckner T, Munzinger $\mathrm{J}$, et al. Prevalence of rotator cuff tear in paraplegic patients compared with controls. J Bone Joint Surg Am. 2010;92:23-30.

4. Sie IH, Waters RL, Adkins RH, Gellman H. Upper extremity pain in the postrehabilitation spinal cord injured patient. Arch Phys Med Rehabil. 1992;73:44-8.

5. Curtis KA, Drysdale GA, Lanza RD, Kolber M, Vitolo RS, West R. Shoulder pain in wheelchair users with tetraplegia and paraplegia. Arch Phys Med Rehabil. 1999;80:453-7.

6. Pentland WE, Twomey LT. Upper limb function in persons with long term paraplegia and implications for independence: part II. Paraplegia. 1994;32:219-24.

7. Gironda RJ, Clark ME, Neugaard B, Nelson A. Upper limb pain in a national sample of veterans with paraplegia. J Spinal Cord Med. 2004;27:120-7.

8. Samuelsson KA, Tropp H, Gerdle B. Shoulder pain and its consequences in paraplegic spinal cord-injured, wheelchair users. Spinal Cord. 2004;42:41-6.

9. Nichols PJ, Norman PA, Ennis JR. Wheelchair user's shoulder? Shoulder pain in patients with spinal cord lesions. Scand J Rehabil Med. 1979;11:29-32.

10. Bayley JC, Cochran TP, Sledge CB. The weight-bearing shoulder. The impingement syndrome in paraplegics. J Bone Joint Surg Am. 1987;69:676-8.

11. Van Drongelen S, Van der Woude LH, Janssen TW, Angenot EL, Chadwick EK, Veeger DH. Mechanical load on the upper extremity during wheelchair activities. Arch Phys Med Rehabil. 2005;86:1214-20.

12. Pellegrini A, Pegreffi F, Paladini P, Verdano MA, Ceccarelli F, Porcellini G. Prevalence of shoulder discomfort in paraplegic subjects. Acta Biomed. 2012;83:177-82.

13. Dyson-Hudson TA, Kirshblum SC. Shoulder pain in chronic spinal cord injury, part I: epidemiology, etiology, and pathomechanics. J Spinal Cord Med. 2004;27:4-17.

14. Eriks-Hoogland IE, Hoekstra T, de Groot S, Stucki G, Post MW, van der Woude LH. Trajectories of musculoskeletal shoulder pain after spinal cord injury: identification and predictors. J Spinal Cord Med. 2014;37:288-98.

15. Akbar M, Brunner M, Balean G, Grieser T, Bruckner T, Loew M, et al. A cross-sectional study of demographic and morphologic features of rotator cuff disease in paraplegic patients. J Shoulder Elbow Surg. 2011;20:1108-13.

16. Gellman H, Chandler DR, Petrasek J, Sie I, Adkins R, Waters RL. Carpal tunnel syndrome in paraplegic patients. J Bone Joint Surg Am. 1988;70:517-9.

17. Goodman CM, Steadman AK, Meade RA, Bodenheimer C, Thornby J, Netscher DT. Comparison of carpal canal pressure in paraplegic and nonparaplegic subjects: clinical implications. Plast Reconstr Surg. 2001;107:1464-71.

18. Yang J, Boninger ML, Leath JD, Fitzgerald SG, Dyson-Hudson TA, Chang MW. Carpal tunnel syndrome in manual wheelchair users with spinal cord injury: a cross-sectional multicenter study. Am J Phys Med Rehabil. 2009;88:1007-16.

19. Aljure J, Eltorai I, Bradley WE, Lin JE, Johnson B. Carpal tunnel syndrome in paraplegic patients. Paraplegia. 1985;23:182-6.

20. Erhan B, Gunduz B, Bardak AN, Ozcan S, Carli A, Er H, et al. Elbow problems in paraplegic spinal cord injured patients: frequency and related risk factors--a preliminary controlled study. Spinal Cord. 2013;51:406-8.

21. Dalyan M, Cardenas DD, Gerard B. Upper extremity pain after spinal cord injury. Spinal Cord. 1999;37:191-5.

22. Muller R, Brinkhof MW, Arnet U, Hinrichs T, Landmann G, Jordan X, et al. Prevalence and associated factors of pain in the Swiss spinal cord injury population. Spinal Cord. 2017:55:346-54.

23. Gellman H, Sie I, Waters RL. Late complications of the weightbearing upper extremity in the paraplegic patient. Clin Orthop Relat Res. 1988;233:132-5.

24. Pentland WE, Twomey LT. Upper limb function in persons with long term paraplegia and implications for independence: part I. Paraplegia. 1994;32:211-8.

25. Barbetta DC, Lopes AC, Chagas FN, Soares PT, Casaro FM, Poletto MF, et al. Predictors of musculoskeletal pain in the upper extremities of individuals with spinal cord injury. Spinal Cord. 2016;54:145-9.

26. Frankel HL, Hancock DO, Hyslop G, Melzak J, Michaelis LS, Ungar GH, et al. The value of postural reduction in the initial management of closed injuries of the spine with paraplegia and tetraplegia. I. Paraplegia. 1969;7:179-92.

27. Siddall PJ, Taylor DA, McClelland JM, Rutkowski SB, Cousins MJ. Pain report and the relationship of pain to physical factors in the first 6 months following spinal cord injury. Pain. 1999;81:187-97.

28. Rose M, Robinson JE, Ells P, Cole JD. Pain following spinal cord injury: results from a postal survey. Pain. 1988;34:101-2.

29. Pentland W, McColl MA, Rosenthal C. The effect of aging and duration of disability on long term health outcomes following spinal cord injury. Paraplegia. 1995;33:367-73.

30. Janssen TW, van Oers CA, van der Woude LH, Hollander AP. Physical strain in daily life of wheelchair users with spinal cord injuries. Med Sci Sports Exerc. 1994;26:661-70.

31. Subbarao JV, Klopfstein J, Turpin R. Prevalence and impact of wrist and shoulder pain in patients with spinal cord injury. J Spinal Cord Med. 1995;18:9-13.

32. Meyer AW. Chronic functional lesions of the shoulder. Arch Surg. 1937;35:646-74.

33. Medina GI, Nascimento FB, Rimkus CM, Zoppi Filho A, Cliquet A Jr.. Clinical and radiographic evaluation of the shoulder of spinal cord injured patients undergoing rehabilitation program. Spinal Cord. 2011;49:1055-61.

34. McCasland LD, Budiman-Mak E, Weaver FM, Adams E, Miskevics S. Shoulder pain in the traumatically injured spinal cord patient: evaluation of risk factors and function. J Clin Rheumatol. 2006;12:179-86.

35. Alm M, Saraste H, Norrbrink C. Shoulder pain in persons with thoracic spinal cord injury: prevalence and characteristics. J Rehabil Med. 2008;40:277-83.

36. Noreau L, Proulx P, Gagnon L, Drolet M, Laramee MT. Secondary impairments after spinal cord injury: a population-based study. Am J Phys Med Rehabil. 2000;79:526-35.

37. Riek LM, Tome J, Ludewig PM, Nawoczenski DA. Improving shoulder kinematics in individuals with paraplegia: comparison across circuit resistance training exercises and modifications in hand position. Phys Ther. 2016;96:1006-17.

38. Sinnott KA, Milburn P, McNaughton H. Factors associated with thoracic spinal cord injury, lesion level and rotator cuff disorders. Spinal Cord. 2000;38:748-53.

39. Seelen HA, Potten YJ, Adam JJ, Drukker J, Spaans F, Huson A. Postural motor programming in paraplegic patients during rehabilitation. Ergonomics. 1998;41:302-16.

40. Seelen HA, Potten YJ, Drukker J, Reulen JP, Pons C. Development of new muscle synergies in postural control in spinal cord injured subjects. J Electromyogr Kinesiol. 1998;8:23-34. 
41. Potten YJ, Seelen HA, Drukker J, Reulen JP, Drost MR. Postural muscle responses in the spinal cord injured persons during forward reaching. Ergonomics. 1999;42:1200-15.

42. Nyland J, Robinson K, Caborn D, Knapp E, Brosky T. Shoulder rotator torque and wheelchair dependence differences of National Wheelchair Basketball Association players. Arch Phys Med Rehabil. 1997;78:358-63.

43. Ballinger DA, Rintala DH, Hart KA. The relation of shoulder pain and range-of-motion problems to functional limitations, disability, and perceived health of men with spinal cord injury: a multifaceted longitudinal study. Arch Phys Med Rehabil. 2000;81:1575-81.

44. Johnson GW, Cadwallader K, Scheffel SB, Epperly TD. Treatment of lateral epicondylitis. Am Fam Physician. 2007;76:843-8.

45. Latko WA, Armstrong TJ, Franzblau A, Ulin SS, Werner RA, Albers JW. Cross-sectional study of the relationship between repetitive work and the prevalence of upper limb musculoskeletal disorders. Am J Ind Med. 1999;36:248-59.

46. Hamilton PG. The prevalence of humeral epicondylitis: a survey in general practice. J R Coll Gen Pract. 1986;36:464-5.

47. Bot SD, van der Waal JM, Terwee CB, van der Windt DA, Schellevis FG, Bouter LM, et al. Incidence and prevalence of complaints of the neck and upper extremity in general practice. Ann Rheum Dis. 2005;64:118-23.

48. Schroer W, Lacey S, Frost FS, Keith MW. Carpal instability in the weight-bearing upper extremity. J Bone Joint Surg Am. 1996;78:1838-43.
49. Francis TGT, Reddappa P. Comparative study on the wrist positions during raise maneuver and their effect on hand function in individuals with paraplegia. Topics in spinal cord injury. Rehabilitation. 2013;19:42-6.

50. Akbar M, Penzkofer S, Weber MA, Bruckner T, Winterstein M, Jung $M$. Prevalence of carpal tunnel syndrome and wrist osteoarthritis in long-term paraplegic patients compared with controls. J Hand Surg Eur Vol. 2014;39:132-8.

51. Luchetti R, Schoenhuber R, Alfarano M, Deluca S, De Cicco G, Landi A. Carpal tunnel syndrome: correlations between pressure measurement and intraoperative electrophysiological nerve study. Muscle Nerve. 1990;13:1164-8.

52. Yoshioka S, Okuda Y, Tamai K, Hirasawa Y, Koda Y. Changes in carpal tunnel shape during wrist joint motion. MRI evaluation of normal volunteers. J Hand Surg Br. 1993;18:620-3.

53. de Krom MC, Knipschild PG, Kester AD, Thijs CT, Boekkooi PF, Spaans F. Carpal tunnel syndrome: prevalence in the general population. J Clin Epidemiol. 1992;45: 373-6.

54. Kaplan Y, Kurt SG, Karaer H. Carpal tunnel syndrome in postmenopausal women. J Neurol Sci. 2008;270: 77-81.

55. Hardoim DG, de Oliveira GB, Kouyoumdjian JA. Carpal tunnel syndrome: long-term nerve conduction studies in 261 hands. Arq Neuropsiquiatr. 2009;67:69-73. 